\title{
Biphasic lung diffusing capacity: detection of early asbestos induced changes in lung function
}

\author{
Željko Dujić, Jadranka Tocilj, Srdjan Boschi, Marko Sarić, Davor Eterović
}

\begin{abstract}
Asbestos related changes in the single breath carbon monoxide diffusing capacity $\left(D_{\mathrm{L}} \mathrm{CO}\right)$ were longitudinally analysed in 14 subjects exposed predominantly to chrysotile asbestos in an asbestos cement factory. These subjects were examined annually over the past nine years; their lung function was initially characterised with increased $D_{L} C O$ as the sole functional abnormality and they had normal chest radiographs. The radiological examination included a chest $x$ ray film and, in the past two years, high resolution computed tomography (HRCT). A biphasic $D_{\mathrm{L}} C O$ change was found: an initial increase followed by a relative decrease. The increase in $D_{L} C O$ was mainly caused by an increase in the membrane component (Dm). Indomethacin treatment applied after the sixth annual follow up significantly reduced $D_{L} C O$ and $D m$. The decrease in $D_{L} C O$ correlated well with the parenchymal abnormalities found on HRCT, whereas the chest $x$ ray film profusion score for small opacities (ILO classification) was unchanged. In conclusion, the data suggested that, as well as the absolute values of pulmonary function tests, the measurement of progression of func-
\end{abstract}

Department of Physiology, University of Zagreb Medical School-Section in Split, 58000 Split, Republic of Croatia

Ž Dujić

Pulmonary Division, Clinical Hospital "Firule" Split, 58000 Split, Republic of Croatia

J Tocilj

Department of Radiology, University of Zagreb

Medical School-Section in Split and Clinical Hospital "Firule" Split, 58000 Split, Republic of Croatia

S Boschi

Institute for Medical Research and Occupational Health, University of Zagreb, 41000 Zagreb, Republic of Croatia

M Sarić

Department of Nuclear Medicine, Clinical Hospital

"Firule" Split, 58000 Split, Republic of Croatia

D Eterovic tional parameters is essential in the assessment of pleural and parenchymal disease of the lung related to exposure to asbestos. High resolution computed tomography is suggested as the radiological method of choice in subjects with an isolated decrease in $D_{L} C O$. Exposure to asbestos can be associated not only with a reduction in $D_{k} C O$, but also with a temporary increase in $D_{L} C O$ caused by a subclinical inflammatory reaction.

The diagnosis of asbestosis is based on a combination of clinical and radiological findings and measured changes in lung function.' Clinical symptoms, physical findings, and functional abnormalities (reductions in forced vital and diffusing capacities) were usually evident only in the advanced stages of disease and appeared too insensitive for early detection of asbestosis. ${ }^{23}$ Recent studies have shown, however, that functional abnormalities may precede roentgenographic changes in the asbestos exposed subjects. $^{46}$ The radiological diagnosis of asbestosis has been recently improved by HRCT, which has increased sensitivity over the standard $x$ ray film or conventional CT for the detection of early pleural and parenchymal changes. ${ }^{7}$

In the present study we performed a nine year follow up and analysed lung function and radiological data in a group of asbestos cement workers, with particular emphasis on single breath carbon monoxide diffusing capacity $\left(D_{L} C O\right)$ and HRCT.

\section{Subjects and methods}

The study population consisted of asbestos cement workers. A continuous survey was started in 1979 with the purpose of investigating asbestos associated health hazards in exposed subjects. The study population was composed of all exposed subjects regardless of whether they had any symptoms. All subjects had complete medical and occupational histories taken and underwent physical examination, resting pulmonary functional tests, and chest radiography. Pulmonary function test results at the end of the sixth follow up indicated that 14 workers of the total number of $215(7 \%)$ had a greater than 
Table 1 Pulmonary function and radiological data in 14 asbestos exposed subjects at the start of nine year follow up period

\begin{tabular}{|c|c|c|c|c|c|c|c|c|}
\hline \multirow[b]{2}{*}{ No } & \multirow[b]{2}{*}{ Expo (y) } & \multicolumn{6}{|c|}{ Functional data } & \multirow{2}{*}{$\begin{array}{l}\text { Chest radiographs } \\
\text { (ILO profusion score) }\end{array}$} \\
\hline & & $D_{L} C O(\%)$ & $D_{L} C O / V A(\%)$ & $D m(\%)$ & $V c(\%)$ & $F V C(\%)$ & $F E V_{1}(\%)$ & \\
\hline Mean (SD) & $12(7)$ & $92(5)$ & $95(4)$ & $101(9)$ & $93(9)$ & $94(5)$ & $94(5)$ & \\
\hline
\end{tabular}

Expo $=$ Duration of asbestos exposure at the start of the study.

$120 \%$ increase in predicted $D_{L} C O$. These 14 workers had normal pulmonary function (including $D_{L} C O$ ) and chest radiographs, and were asymptomatic at the start of the study (table 1). They had been involved in manufacture of asbestos cement products, where chrysotile asbestos has been predominantly used. Their average age was 42 (SD 8) years with a mean asbestos exposure of 21 (SD 6) years at the end of the nine year follow up period. They formed the study population and comprised 11 non-smokers and three smokers.

Pulmonary function testing included measurements of the forced vital capacity (FVC), and the forced expiratory volume in one second $\left(\mathrm{FEV}_{1}\right)$. The best of three readings was chosen on the basis of the

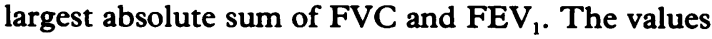
obtained were expressed as percentages of the predicted values. ${ }^{8}$ Measurement of $\mathrm{D}_{\mathrm{L}} \mathrm{CO}$ was with the single breath technique in an upright seated position (Morgan MK-4, England). ${ }^{9}$ The same equipment was used for all nine follow ups in $D_{L} C O$ measurements. For single breath (10 second breath hold) $\mathrm{D}_{\mathrm{L}} \mathrm{CO}$ measurements, an inspired concentration of $0.3 \% \mathrm{CO}, 9 \% \mathrm{He}, 21 \% \mathrm{O}_{2}$, and balance nitrogen was used. The arithmetic mean of two acceptable tests for each subject was used and $\mathrm{D}_{\mathrm{L}} \mathrm{CO}$ values were corrected for haemoglobin concentration. ${ }^{10}$ Estimations of the membrane diffusing component (Dm) and the pulmonary capillary blood volume (Vc) were done according to the methods of Roughton and Forster. ${ }^{11}$ Measurements of $\mathrm{D}_{\mathrm{L}} \mathrm{CO}$ were made at two alveolar oxygen tensions, namely, during inhalation of room air and after breathing $100 \% \mathrm{O}_{2}$ for 20 minutes. Bates' equation $\left(1 / \Theta=0.0057 \mathrm{PAO}_{2}+0.75\right)$ and a $\lambda$ value of 2.5 were used for estimation of $\mathrm{D}_{\mathrm{L}} \mathrm{CO} \cdot{ }^{12}$ Reference values for $D_{L} C O, D_{L} C O / V A, D m$, and Vc were taken from Cotes. ${ }^{13}$ All 14 subjects were without any clinical abnormalities known to affect $\mathrm{D}_{\mathrm{L}} \mathrm{CO}$ volume (anaemia, asthma).

After the sixth annual follow up all 14 subjects were offered $125 \mathrm{mg}$ of indomethacin per day for seven days and they consumed the drug regularly. The transfer factor and its components (Dm and Vc) were measured the day after completion of the treatment.

Radiological examination included posteroanterior and lateral chest radiographs, which were scored independently by two thoracic radiologists trained in the ILO international classification for pneumoconioses. ${ }^{14}$ The HRCT was performed in all subjects with a Siemens SOMATOM scanner. Scans were made at five levels through the lower thorax in both prone and supine positions for a total of 10 images. ${ }^{15}$ Scans were acquired at full expiration by using $2 \mathrm{~mm}$ thickness, seven second scan acquisition time, 720 projections, $125 \mathrm{kV}, 780 \mathrm{mAs}$, and a strong edge enhancement algorithm. All HRCT scans were photographed at three window settings-namely for the pleura and mediastinum, for the lungs, and for the lung and pleura. The HRCT scoring was done according to Aberle and coworkers ${ }^{7}$ by two radiologists and the probability for asbestosis was scored on a five point scale (from $1=$ normal, to $5=$ abnormal and high probability for asbestosis).

Statistical analysis was performed with the paired Student's $t$ test and p $<0.05$ was taken as the level of significance. For comparison of the various functional and imaging tests Pearson's correlation was used.

\section{Results}

At the start of the study, all subjects had normal lung function and chest radiographs (table 1 ). The onset of exposure to asbestos ranged individually from two to 23 years. At the sixth follow up, their lung function 
Table 2 Pulmonary function and radiological data in 14 asbestos exposed subjects at sixth follow up

\begin{tabular}{|c|c|c|c|c|c|c|c|c|}
\hline \multirow[b]{2}{*}{ No } & \multirow[b]{2}{*}{$\operatorname{Expo}(y)$} & \multicolumn{6}{|c|}{ Functional data } & \multirow{2}{*}{$\begin{array}{l}\text { Chest radiographs } \\
\text { (ILO profusion score) }\end{array}$} \\
\hline & & $D_{L} C O(\%)$ & $D_{L} C O / V A(\%)$ & $\operatorname{Dm}(\%)$ & $V c(\%)$ & $F V C(\%)$ & $F E V_{1}(\%)$ & \\
\hline $\begin{array}{r}1 \\
2 \\
3 \\
4 \\
5 \\
6 \\
7 \\
8 \\
9 \\
10 \\
11 \\
12 \\
13 \\
14\end{array}$ & $\begin{array}{r}28 \\
10 \\
14 \\
9 \\
25 \\
22 \\
19 \\
12 \\
7 \\
24 \\
19 \\
12 \\
15 \\
17\end{array}$ & $\begin{array}{l}133 \\
148 \\
153 \\
152 \\
162 \\
157 \\
131 \\
140 \\
150 \\
141 \\
144 \\
136 \\
152 \\
128\end{array}$ & $\begin{array}{l}140 \\
146 \\
173 \\
163 \\
174 \\
161 \\
148 \\
108 \\
146 \\
158 \\
152 \\
143 \\
135 \\
136\end{array}$ & $\begin{array}{l}147 \\
143 \\
164 \\
161 \\
150 \\
121 \\
173 \\
128 \\
133 \\
146 \\
138 \\
148 \\
152 \\
142\end{array}$ & $\begin{array}{r}102 \\
124 \\
116 \\
104 \\
129 \\
94 \\
108 \\
92 \\
94 \\
114 \\
88 \\
132 \\
104 \\
86\end{array}$ & $\begin{array}{l}90 \\
76 \\
95 \\
85 \\
93 \\
92 \\
97 \\
90 \\
98 \\
93 \\
94 \\
98 \\
94 \\
92\end{array}$ & $\begin{array}{r}96 \\
93 \\
88 \\
86 \\
93 \\
96 \\
88 \\
94 \\
93 \\
95 \\
106 \\
94 \\
90 \\
89\end{array}$ & $\begin{array}{l}0 / 0 \\
0 / 0 \\
0 / 0 \\
0 / 0 \\
0 / 0 \\
0 / 0 \\
0 / 0 \\
0 / 0 \\
0 / 0 \\
0 / 0 \\
0 / 0 \\
0 / 0 \\
0 / 0 \\
0 / 0\end{array}$ \\
\hline Mean (SD) & $17(6)$ & $144(10)$ & $149(16)$ & $146(14)$ & $107(14)$ & $92(6)$ & $93(5)$ & \\
\hline
\end{tabular}

Table 3 Pulmonary function and radiological data in 14 asbestos exposed subjects at the end of nine year follow up period

\begin{tabular}{|c|c|c|c|c|c|c|c|c|c|}
\hline \multirow[b]{2}{*}{ No } & \multirow[b]{2}{*}{$\operatorname{Expo}(y)$} & \multicolumn{6}{|c|}{ Functional data } & \multicolumn{2}{|c|}{ Radiological data } \\
\hline & & $\overline{D_{L} C O(\%)}$ & $D_{L} C O / V A(\%)$ & $\operatorname{Dm}(\%)$ & $V c(\%)$ & $F V C(\%)$ & $F E V_{1}(\%)$ & $\begin{array}{l}\text { ILO profusion } \\
\text { score }\end{array}$ & $\begin{array}{l}\text { HRCT } \\
P A R E\end{array}$ \\
\hline $\begin{array}{r}1 \\
2 \\
3 \\
4 \\
5 \\
6 \\
7 \\
8 \\
9 \\
10 \\
11 \\
12 \\
13 \\
14\end{array}$ & $\begin{array}{l}32 \\
14 \\
18 \\
13 \\
29 \\
26 \\
23 \\
16 \\
11 \\
28 \\
23 \\
16 \\
19 \\
21\end{array}$ & $\begin{array}{r}96 \\
119 \\
108 \\
88 \\
113 \\
82 \\
85 \\
104 \\
92 \\
112 \\
101 \\
118 \\
111 \\
97\end{array}$ & $\begin{array}{r}103 \\
126 \\
113 \\
108 \\
125 \\
85 \\
88 \\
114 \\
97 \\
121 \\
112 \\
128 \\
115 \\
104\end{array}$ & $\begin{array}{r}108 \\
126 \\
106 \\
93 \\
126 \\
91 \\
90 \\
113 \\
107 \\
132 \\
108 \\
127 \\
125 \\
109\end{array}$ & $\begin{array}{r}87 \\
117 \\
109 \\
85 \\
114 \\
85 \\
94 \\
101 \\
97 \\
120 \\
90 \\
122 \\
93 \\
85\end{array}$ & $\begin{array}{r}89 \\
71 \\
101 \\
75 \\
92 \\
87 \\
96 \\
92 \\
96 \\
91 \\
94 \\
100 \\
91 \\
88\end{array}$ & $\begin{array}{r}95 \\
88 \\
92 \\
83 \\
90 \\
94 \\
95 \\
96 \\
94 \\
95 \\
101 \\
93 \\
95 \\
91\end{array}$ & $\begin{array}{l}0 / 0 \\
0 / 1 \\
0 / 0 \\
0 / 0 \\
0 / 0 \\
0 / 1 \\
0 / 0 \\
0 / 0 \\
0 / 0 \\
0 / 0 \\
0 / 0 \\
0 / 0 \\
0 / 0 \\
0 / 0 \\
0 / 1\end{array}$ & $\begin{array}{l}2 \\
2 \\
1 \\
3 \\
2 \\
2 \\
2 \\
1 \\
2 \\
1 \\
2 \\
1 \\
2 \\
2\end{array}$ \\
\hline $\operatorname{Mean}(\mathrm{SD})$ & $21(6)$ & $102(12)$ & $110(13)$ & $111(14)$ & $98(14)$ & $90(8)$ & $93(5)$ & & \\
\hline
\end{tabular}

HRCT PARE = HRCT score for probability for parenchymal fibrosis (1 (low probability) indicates no parenchymal disease; 2 (intermediate probability) indicates parenchymal disease with possible relation to asbestosis; and 3 (high probability) indicates parenchymal asbestosis).

was characterised by the following findings compared with data collected during the first follow up: increased $D_{L} C O \quad(p<0.0001), \quad D_{L} C O / V A$ $(\mathrm{p}<0.0005), \mathrm{Dm}(\mathrm{p}<0.0005)$, and $\mathrm{Vc}(\mathrm{p}<0.01)$ (table 2). Chest radiographs were normal (table 2). The last follow up showed that all subjects had $\mathrm{D}_{\mathrm{L}} \mathrm{CO}, \mathrm{D}_{\mathrm{L}} \mathrm{CO} / \mathrm{VA}, \mathrm{Dm}$, and $\mathrm{Vc}$ in the normal range $( \pm 20 \%$ of the predicted values), whereas two subjects had FVC below $80 \%$ (table 3 ); $\mathrm{D}_{\mathrm{L}} \mathrm{CO}$ $(p<0.05)$ and $D_{L} C O / V A(p<0.01)$ were still increased, however, when compared with the findings in the first follow up. Pleural inickening was found in four subjects (three focal and one diffuse) on the chest $x$ ray film. Pleural thickening was seen on HRCT in six subjects, including the four subjects with pleural thickening on chest $x$ ray film. All subjects had an ILO profusion score for small opacities (an index for parenchymal abnormalities) below $1 / 0$ (table 3 ). The
Table 4 Correlation between various functional and imaging tests in 14 asbestos exposed subjects at the end of nine year follow up

\begin{tabular}{|c|c|c|}
\hline Correlation ${ }^{\star}$ & $r$ & p Value \\
\hline 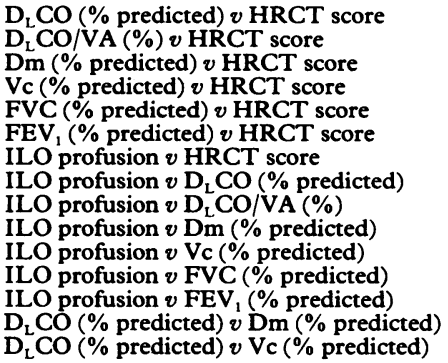 & $\begin{array}{l}0 \cdot 650 \\
0 \cdot 545 \\
0 \cdot 586 \\
0 \cdot 689 \\
0 \cdot 574 \\
0 \cdot 359 \\
0 \cdot 389 \\
0 \cdot 112 \\
0 \cdot 199 \\
0 \cdot 109 \\
0 \cdot 167 \\
0 \cdot 530 \\
0 \cdot 258 \\
0 \cdot 927 \\
0 \cdot 817\end{array}$ & $\begin{array}{l}0.012 \\
0.042 \\
0.029 \\
0.008 \\
0.030 \\
\text { NS } \\
\text { NS } \\
\text { NS } \\
\text { NS } \\
\text { NS } \\
\text { NS } \\
0.049 \\
\text { NS } \\
0.00012 \\
0.00025\end{array}$ \\
\hline
\end{tabular}

${ }^{\star}$ Pearson's correlation; NS $=$ not significant. 
HRCT analysis showed nine subjects, four subjects, and one subject to have intermediate, low, and high probabilities for developing asbestosis respectively (table 3).

Table 4 shows the statistical correlations between the various functional and imaging tests using Pearson's correlation. The HRCT had a higher correlation with functional tests and was possibly more sensitive than conventional chest radiography, although the small sample size $(n=14)$ makes this conclusion tentative.

Figure 1 shows the individual $\mathrm{D}_{\mathrm{L}} \mathrm{CO}$ changes in exposed subjects during the nine years of follow up. A biphasic change in $D_{L} C O$ was noted-namely, an initial increase followed by a relative decrease. The timing of the increase in $\mathrm{D}_{\mathrm{L}} \mathrm{CO}$ in relation to the start of exposure to asbestos was individual. Because VA was unchanged, $D_{L} C O / V A$ changed in a similar manner to $D_{L} C O$ (fig 2). Figures 3 and 4 show the individual $\mathrm{Dm}$ and Vc changes. The initial $\mathrm{D}_{\mathrm{L}} \mathrm{CO}$ increase was mainly due to an increase in $\mathrm{Dm}$, but not in $\mathrm{Vc}$.

Figures 5 and 6 show the effect of indomethacin treatment for seven days on $\mathrm{D}_{\mathrm{L}} \mathrm{CO}, \mathrm{Dm}$, and $\mathrm{Vc}$ in 14 subjects after the sixth annual follow up. When compared with the corresponding pretreatment findings, mean $D_{L} C O$ and $\mathrm{Dm}$ showed a significant reduction after treatment. On the other hand, indomethacin treatment had no effect on Vc.

\section{Discussion}

Lung function tests were suggested to be more sensitive than chest radiographs in detection of early asbestosis. ${ }^{16}$ An increase in static elastic recoil pressure was reported in asbestos exposed subjects, but this test is non-specific and unsuitable for routine measurements. ${ }^{17}$ Measurement of $\mathrm{D}_{\mathrm{L}} \mathrm{CO}$ is another sensitive functional test for the diagnosis of asbestosis. Picado and coworkers ${ }^{16}$ found only 10 patients with decreased $D_{L} C O$ in a group of 42 patients with diagnosed asbestosis. The same authors suggested that $\mathrm{D}_{\mathrm{L}} \mathrm{CO}$ changes do not regress, so that progressive reduction in $\mathrm{D}_{\mathrm{L}} \mathrm{CO}$ may be a reliable finding for the diagnosis of asbestosis. ${ }^{16}$ We have shown previously that functional abnormalities may precede radiological changes in asbestos exposed subjects; the FVC and $D_{L} C O$ decrements were seen with ILO profusion score below $1 / 1,{ }^{5}$ and a biphasic mid-expiratory change in flow rate (the initial

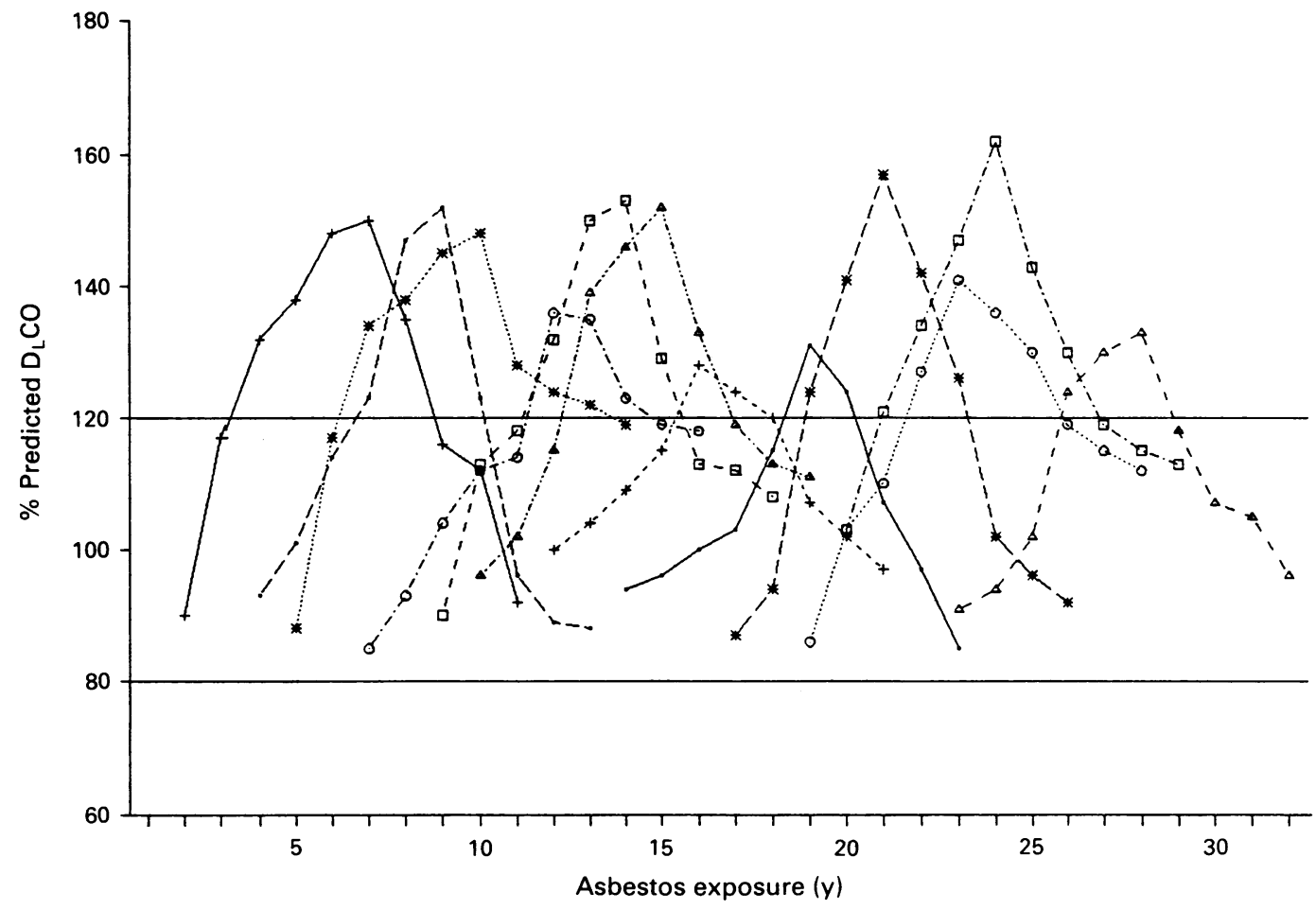

Figure 1 The time course of the individual $D_{L} C O$ changes in 14 asbestos exoposed workers during nine years of follow up. The values are expressed as per cent of the predicted normal values. Horizontal lines represent limits of the normal range. 


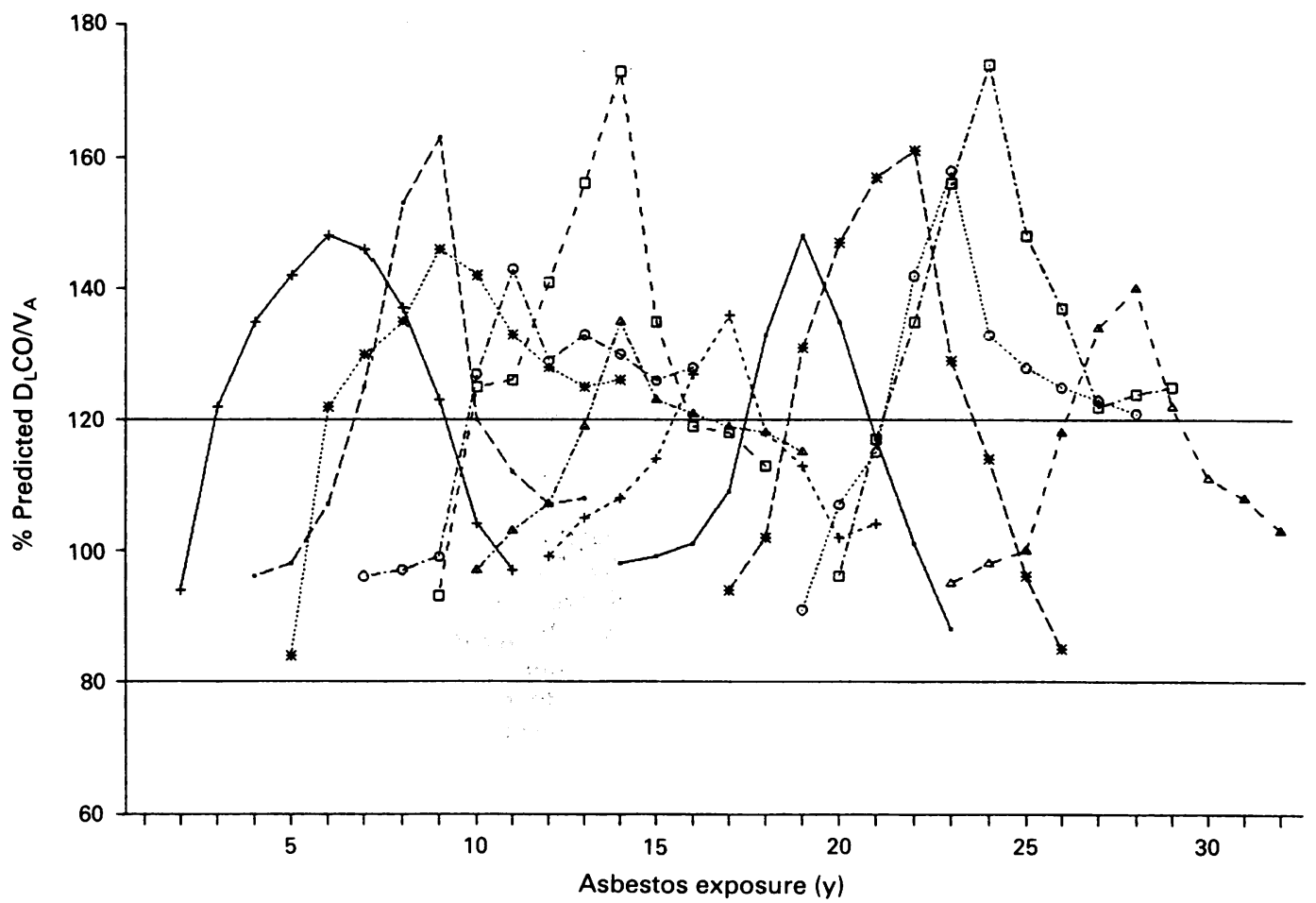

Figure 2 The time course of the individual $D_{L} C O / V A$ changes in 14 asbestos exposed workers during nine years of follow up. Horizontal lines represent limits of the normal range.

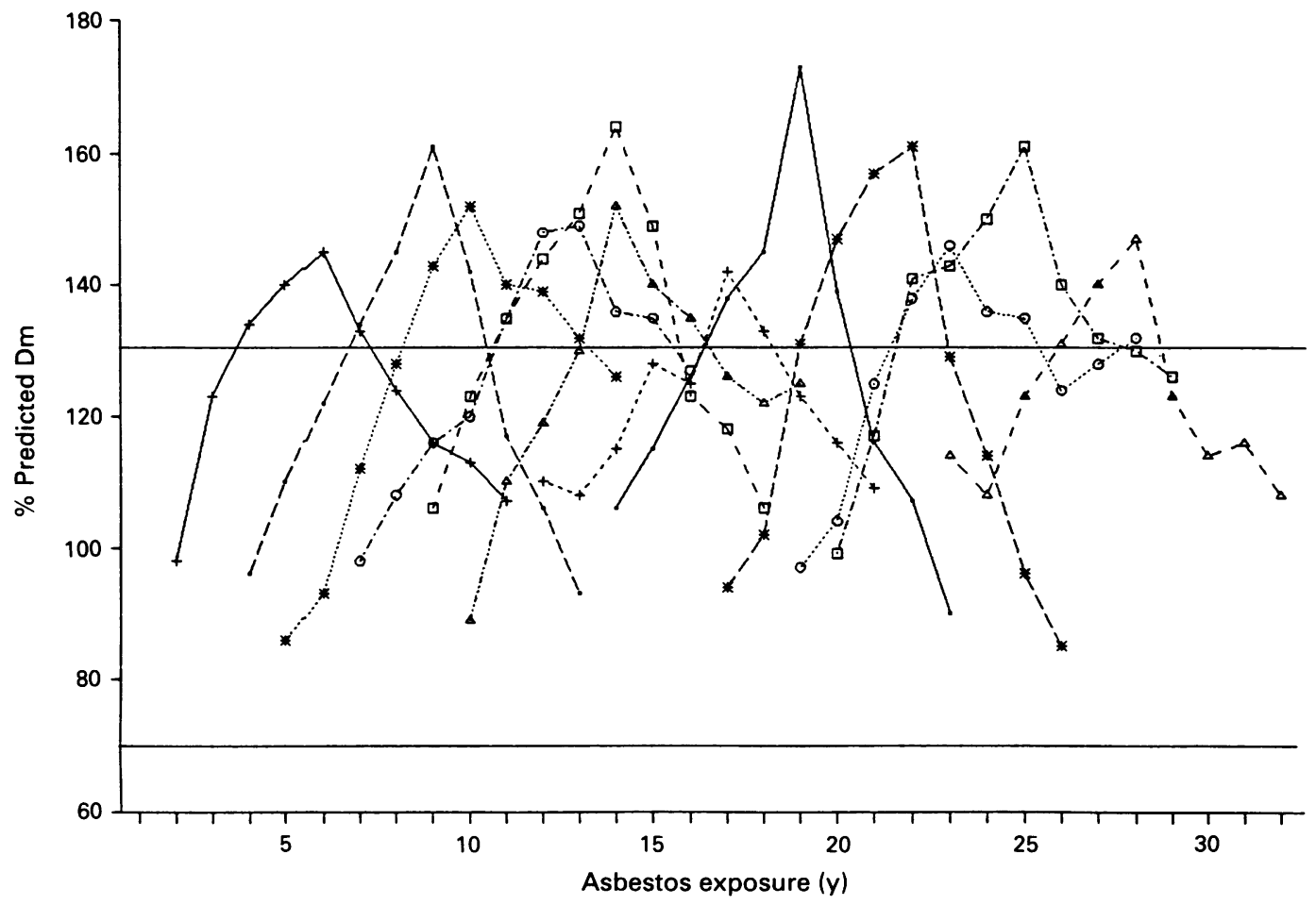

Figure 3 The time course of the individual Dm changes in 14 asbestos exposed workers during nine years of follow up. Horizontal lines represent limits of the normal range. 


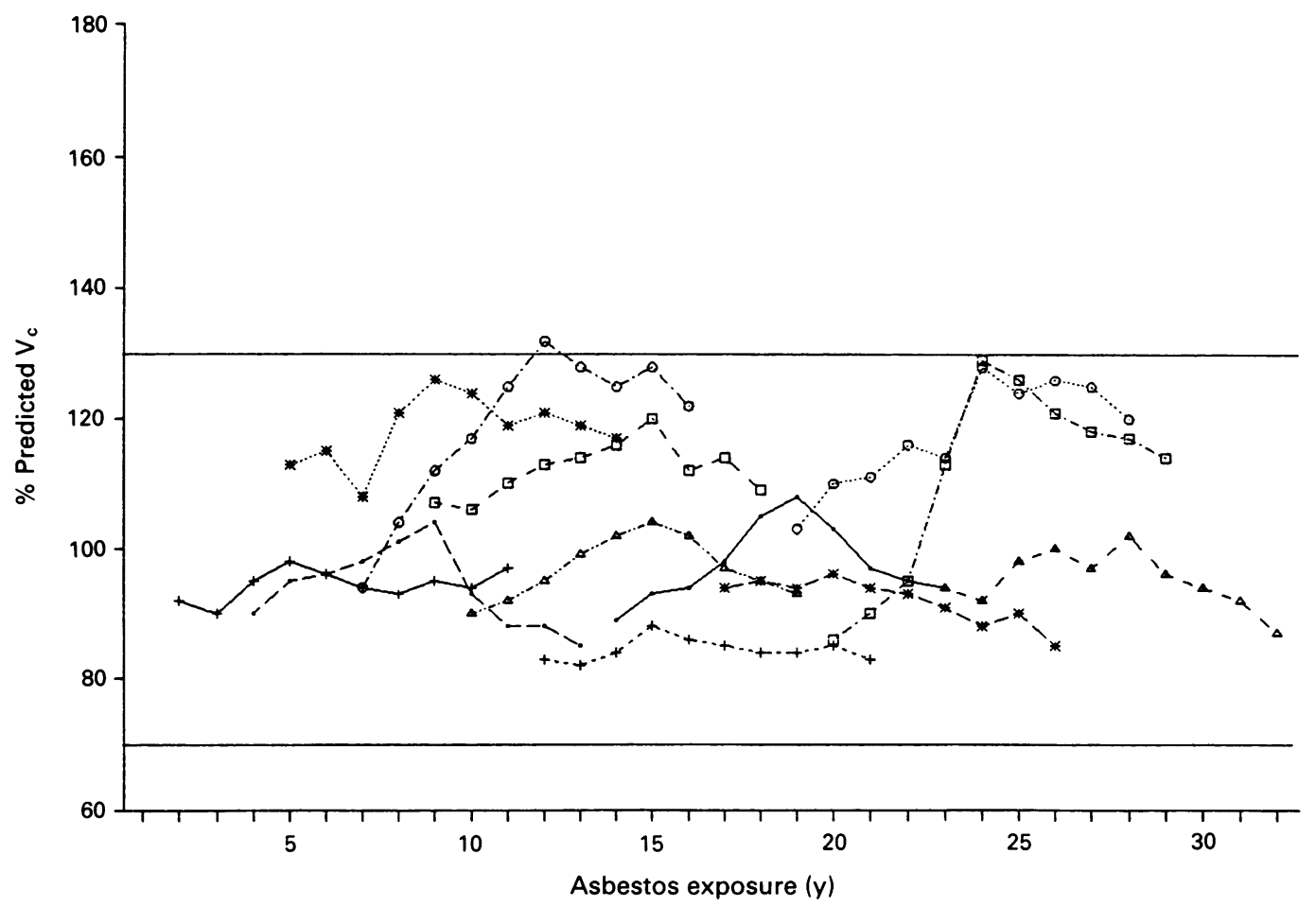

Figure 4 The time course of the individual $V c$ changes in 14 asbestos exposed workers during nine years of follow up. Horizontal lines represent limits of the normal range.

increase followed by a decrease) in some non-smoking workers was the earliest functional sign indicative of the future development of parenchymal asbestosis. ${ }^{6}$ In most subjects, mid-expiratory flow rate and $\mathrm{D}_{\mathrm{L}} \mathrm{CO}$ decrements were correlated with abnormal HRCT suggestive of asbestosis, whereas chest radiographs were unchanged. ${ }^{6}$

The present study showed that in some subjects functional abnormalities precede radiological (chest $x$ ray film) findings. A biphasic change in $\mathrm{D}_{\mathrm{L}} \mathrm{CO}$ was

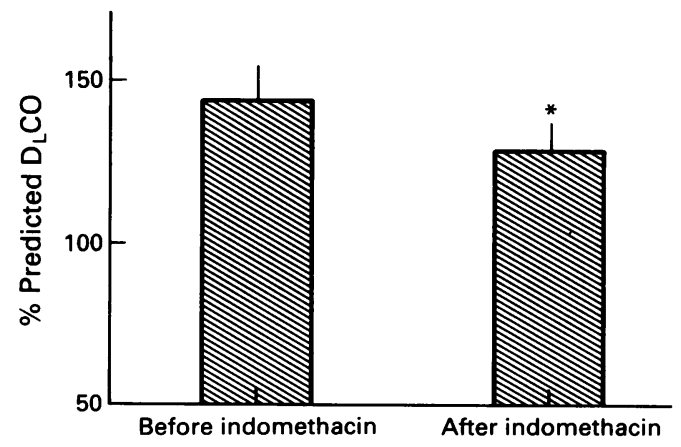

Figure 5 The effect of indomethacin (125 mg once a day for seven days) on $D_{L} C O$ after the sixth annual follow up $(n=14)$. Values are mean with $S D .{ }^{\star} p<0.01$ compared with pretreatment mean values. found-namely, an initial increase, as the earliest functional sign of exposure to asbestos, followed by a relative decrease. This functional response $\left(D_{L} C O\right.$ increase) was timed individually in relation to the start of exposure to asbestos (fig 1). After radiological abnormalities were found (as detected with HRCT

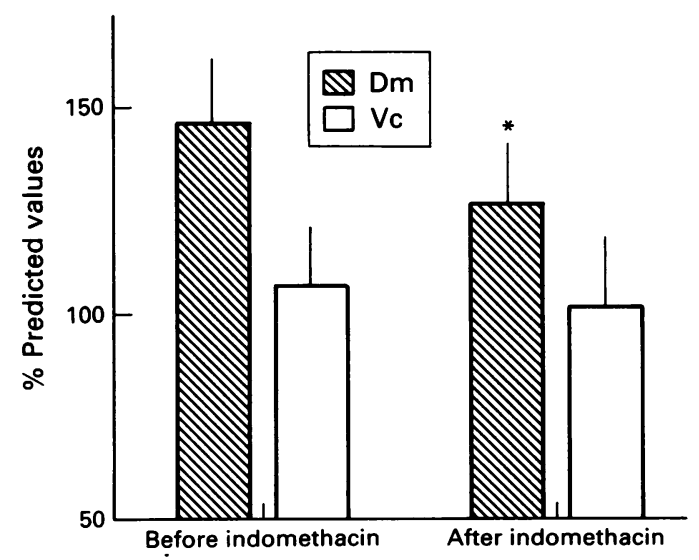

Figure 6 The effect of indomethacin (125 mg once a day for seven days) on Dm and $V c$ after the sixth annual follow up $(n=14)$. Values are mean with $S D .{ }^{\star} p<0.01$ compared with pretreatment mean values. 
but not on the chest $x$ ray films), a relative decrease in $\mathrm{D}_{\mathrm{L}} \mathrm{CO}$ was seen, but the absolute values were still in the normal range of the predicted values. Despite this fact, these subjects had a substantial decrease in $\mathrm{D}_{\mathrm{L}} \mathrm{CO}$ relative to the values observed in the previous few years of the follow up.

Another problem in the assessment of tests of pulmonary function is the fairly wide range of predicted values $( \pm 20 \%)$. Theoretically, a subject could start with an FVC or $D_{L} C O$ of $120 \%$ of predicted values, and despite a large reduction (up to $40 \%$ ), still be described as "functionally normal". This emphasises the need for establishing dynamic measurements of lung function as the main determinant in the diagnosis and prognosis of pulmonary disease.

The early phase of asbestosis can be characterised by multifocal inflammatory responses and it has been named "chronic interstitial pneumonia" ${ }^{18}$ Pulmonary uptake of gallium was found to be increased in many subjects without roentgenographic changes associated with asbestosis, but who had been exposed either to chrysotile ${ }^{19}$ or crocidolite. ${ }^{20}$ This suggested the presence of subclinical pulmonary inflammation in these subjects. In a recent report, Garcia and coworkers ${ }^{21}$ showed that asbestos fibres can increase the release of prostaglandin $\mathrm{PGI}_{2}$ from the endothelial cell monolayer in a dose-dependent manner in vitro. As an active pulmonary vasodilator, ${ }^{22} \mathrm{PGI}_{2}$ may increase the pulmonary blood volume. The process of inflammation is associated with local vasodilatation and increased blood volume. As inhalation of asbestos fibres leads to chronic multifocal inflammatory response, it is possible that $D_{L} C O$ was initially increased in our subjects due to the increase in the pulmonary capillary blood volume. The membrane diffusion (Dm) and the pulmonary capillary blood volume (Vc) changed in a manner similar to $D_{L} C O$ in our subjects (table 2), but most of the increase in $\mathrm{D}_{\mathrm{L}} \mathrm{CO}$ was due to an increase in $\mathrm{Dm}$. It has been shown that dynamic exercise induces similar changes in Dm and Vc. ${ }^{23}$ Possible mechanisms for these effects during exercise are the opening of capillaries of smaller diameter or thinner walls, and stretching of the capillaries to produce flattening of their cross section, and thinning of their walls. ${ }^{23}$ The possible explanation of the finding that the increase in $\mathrm{D}_{\mathrm{L}} \mathrm{CO}$ in our subjects was predominantly caused by an increase in Dm could be the enhanced solubility of $\mathrm{CO}$ in an inflamed environment, rather then a decrease in the thickness of the alveolocapillary membrane.

To test the hypothesis that an asbestos induced increase in $D_{L} C O$ was caused by increased local prostaglandin production, we investigated the effect of seven day indomethacin treatment in our subjects after the sixth annual follow up (figs 5 and 6 ). Indomethacin, an inhibitor of prostaglandin synth- etase (cyclooxygenase), caused significant reductions in $\mathrm{D}_{\mathrm{L}} \mathrm{CO}$ and $\mathrm{Dm}$ in comparison with pretreatment values. Post-treatment $D_{L} C O$ and $D m$ values were, however, still above those predicted. The possible explanation for this discrepancy could be asbestos induced increased concentrations of other local vasodilators known to be released in inflammatory reactions (for example, histamine, bradykinin).

Recently, HRCT has been shown to be more sensitive than chest radiography in detecting pleural and parenchymal pulmonary abnormalities. ${ }^{74}$ Staples $e t a^{24}$ reported that in 169 asbestos exposed subjects with no evidence of asbestosis on chest radiographs (ILO grade $<1 / 0$ ), $34 \%$ had abnormalities on HRC consistent with asbestosis. Our data, although limited by the small sample size ( $n=14)$, also support the argument that HRCT has a higher correlation with functional tests and that it may be more sensitive than conventional chest radiography in asbestos exposed subjects. We found pleural thickening on HRCT in six out of 14 subjects, although this was mild in five of them. In all six subjects, parenchymal abnormalities were also present on HRCT, thus preventing the selective investigation of the effects of isolated pleural thickening on pulmonary function. Staples $e t a^{24}$ reported that pulmonary function in subjects with pleural plaques on HRCT was not significantly different from those without pleural plaques when parenchymal analysis by HRCT was normal.

In conclusion, our data show that dynamic functional findings precede radiological abnormalities on the chest $x$ ray film in some subjects exposed to asbestos. The radiological method of choice in the early detection of asbestosis, indicated by reduction in $\mathrm{D}_{\mathrm{L}} \mathrm{CO}$ is considered to be HRCT, as suggested by other investigators. Our results suggest that exposure to asbestos can lead to a biphasic change in $\mathrm{D}_{\mathrm{L}} \mathrm{CO}$ (initial increase followed by relative decrease) and that $D_{L} C O$ might be an early and sensitive functional indicator of future interstitial asbestosis. The initial increase in $\mathrm{D}_{\mathrm{L}} \mathrm{CO}$ was probably due to a subclinical inflamatory response. Prostaglandins seem to be one of the inflammatory mediators of an increase in $\mathrm{D}_{\mathrm{L}} \mathrm{CO}$ as indicated by a partial return of $\mathrm{D}_{\mathrm{L}} \mathrm{CO}$ to normal after treatment with indomethacin.

Requests for reprints to: Dr $\check{Z}$ Dujić, Department of Physiology, University of Zagreb Medical SchoolSection in Split, IL Ribara 4, 58000 Split, Republic of Croatia.

1 Becklake MR. Asbestos-related diseases of the lung and other organs; their epidemiology and implications for clinical practice. Am Rev Respir Dis 1976;114:187-227.

2 Begin R, Cantin A, Berthiaume Y, et al. Clinical features to stage alveolitis in asbestos workers. Am J Ind Med 1985;8:521-36.

3 Parkes WR. Asbestos-related disorders. British Journal of Diseases of the Chest 1973;61:261-300.

4 Rosenstock L, Barnhart S, Heyer NJ, et al. The relation among 
pulmonary function, chest roentgenographic abnormalities, and smoking status in an asbestos-exposed cohort. $\mathrm{Am} \mathrm{Rev}$ Respir Dis 1988;138:272-7.

5 Tocilj J, Dujic Z, Boschi S, Saric M. Correlation of radiological and functional findings in workers exposed to chrysotile asbestos. Med Lav 1990;81:373-81.

6 Dujić $Z$, Tocilj J, Sarić M. Early detection of interstitial lung disease in asbestos exposed non-smoking workers by midexpiratory flow rate and high resolution computed tomography. Br J Ind Med 1991;48:663-4.

7 Aberle DR, Gamsu G, Ray CS. High-resolution CT of benign asbestos-related diseases: clinical and radiographic correlation. American Journal of Roentgenology 1988;151:883-91.

8 Cotes JE, Hall AM. The transfer factor for the lung; normal values in adults. In: Arcangeli P, ed. Normal values for respiratory function in man. Torino: Panminerva Medica, 1970:327-43.

9 Crapo RO, Gardner RM. Single breath carbon monoxide diffusing capacity (transfer factor)-Recommendations for a standard technique. Am Rev Respir Dis 1987;136:1299-307.

10 Cotes JE, Dabbs JM, Elwood PC, Hall AM, McDonald A Saunders MJ. Iron deficiency anemia: its effect on transfer factor for the lung (diffusing capacity), ventilation and cardiac frequency during sub-maximal exercise. Clin Sci 1972; 42:325-35.

11 Roughton FJW, Forster RE. Relative importance of diffusion and chemical reaction rates in determining rate of exchange of gases in the human lung. With special references to true diffusing capacity of pulmonary membrane and volume of blood in the lung capillaries. $J$ Appl Physiol 1957;11:290-302.

12 Bates DV, Varvis CJ, Donevan RE, Christie RV. Variation in the pulmonary capillary blood volume and membrane diffusing component in health and disease. J Clin Invest 1960;39: 1401-12.

13 Cotes JE. Lung function at different stages of life, including reference values. In: Cotes JE, ed. Lung function. London:
Blackwell Scientific Publications, 1975:340-95.

14 International Labour Organisation. Guidelines for the use of ILO international classification of radiographs of pneumoconioses (revised edition). Geneva: ILO, 1980.

15 Aberle DR, Gamsu G, Ray CS, Feuerstein IM. Asbestos-related pleural and parenchymal fibrosis: detection with high-resolution CT. Radiology 1988;166:729-34.

16 Picado C, Rodriguez-Roisin R, Sala H, Agusti-Vidal A. Diagnosis of asbestosis. Lung 1984;162:325-35.

17 Jodoin G, Gibbs GW, Macklem PT, McDonald JC, Becklake MR. Early effects of asbestos exposure on lung function. $\mathrm{Am}$ Rev Respir Dis 1971;104:525-35.

18 Epler GR, Fitzgerald MX, Gaensler EA, Carrington CB. Asbestos-related disease from household exposure. Respiration 1980;39:229-40.

19 Begin R, Cantin A, Berthianme Y. Clinical features to stage alveolitis in asbestos workers. Am J Ind Med 1985;8:521-36.

20 Hayes AA, Mullan B, Lovegrove FT, Rose AH, Musk AW, Robinson BW. Gallium lung scanning and bronchoalveolar lavage in crocidolite-exposed workers. Chest 1989;96:22-6.

21 Garcia JGN, Gray LD, Dodson RF, Callahan KS. Asbestosinduced endothelial cell activation. Am Rev Respir Dis 1988; 138:958-64.

22 Jones K, Higenbottan T, Wallwork J. Pulmonary vasodilatation with prostacycline in primary and secondary pulmonary hypertension. Chest 1989;96:784-9.

23 Anderson TW, Shepard RJ. The effects of hyperventilation and exercise upon the pulmonary diffusing capacity. Respiration 1968;25:465-84.

24 Staples CA, Gamsu G, Ray CS, Webb WR. High resolution computed tomography and lung function in asbestos-exposed workers with normal chest radiographs. Am Rev Respir Dis 1989;139:1502-8.

Accepted 19 August 1991
The British Journal of Industrial Medicine welcomes correspondence relating to any of the material appearing in the journal. Results from preliminary or small scale studies may also be published in the correspondence column if this seems appropriate. Letters should be not more than $\mathbf{5 0 0}$ words in length and contain a minimum of references. Table and figures should be kept to an absolute minimum. Letters are accepted on the understanding that they may be subject to editorial revision and shortening.

The journal now also publishes editorials which are normally specially commissioned. The Editor welcomes suggestions regarding suitable topics; those wishing to submit an editorial, however, should do so only after discussion with the Editor. 